\title{
Postgraduate supervisor development through ICT
}

Peter Kandlbinder, Institute for Teaching and Learning, University of Sydney

\section{Introduction}

The expectations of postgraduate students are changing as many more students consider a Ph.D. to be a professional degree rather than simply research training (Pearson, 1999). These kinds of expectations however are superimposed on already well-formulated views of what constitutes a Ph.D. It is not surprising, then, that students complain regularly that they do not receive sufficient guidance on the expectations of the candidature or that their number one complaint is communication breakdown between students and supervisors (Philips and Pugh, 1994).

When it comes to discussing their own experiences of being a Ph.D. student, postgraduate supervisors at the University of Sydney often describe feeling they had received their Ph.D. despite their supervision rather than because of it. A typical comment would be:

' 1 really came out of it feeling like I really did this on my own and I didn't do a very good job. 1don't want it to be like that with anyone else."*

While most successful supervisors continue to report a very good relationship with their own supervisor, even after receiving their degree, it is not uncommon to describe the experience as one of being left to fend for themselves based on the philosophy that the cream will rise to the top. Concerns are regularly expressed by current candidates that this does not always deliver a high-quality experience for postgraduate students. As time constraints increase, Ph.D.'s have little alternative but to become much more structured and well defined. The misalignment between supervisors and candidates is defined as a waste of resources (Grant and Graham, 1994), which shifts the focus of improvement of supervision to tips and techniques to make the system more efficient rather than a more open, negotiated approach (Acker et al., 1994).

\footnotetext{
* All quotations included in this chapter are taken from interviews with thirty successful supervisors at the University of Sydney (for more information see Kandlbinder \& Peseta, 1999)
} 
Without a clear idea of how postgraduates learn, or the supervisor's role in the process, it is not surprising that most advice attempts to define supervision as another form of teaching. This in itself demonstrates that postgraduate supervisor pedagogy, as a distinct form of supervisor/ student interaction, is not well understood. Students, coordinators and government bodies are all searching for a way to enhance the supervisory processes through a regulatory framework. Our programme for developing supervision chose to model the flexibility that assists supervisors in appreciating the unique circumstances of their students.

\section{Developing Flexible Supervisors}

While there is general agreement that being a good researcher plays an important role in mentoring students into a discipline it has been recognised for some time that this alone is not enough to become a good research supervisor (Moses, 1985). There is the personal nature to the commitment to undertake either research or supervision that gets in the way of any robust notion of pedagogy of supervisor development. With supervision taking place away from public view, where we are unlikely to be privy to these negotiations, it is little wonder that improvement of postgraduate supervision is left to advice from those who consider their own experience a success, whether directed at the supervisor (see e.g. Delamont et al., 1997) or the student (see e.g. Stevens and Asmar, 1999).

The individualised, negotiated, often serendipitous nature of supervision makes it a challenge for academic development. Research supervision is a complex practice characterised by a divergence of approaches and expectations, with each candidature individually negotiated between the supervisor, candidate and department. Few other than the largest schools or departments have a formal programme of induction for supervisors new to supervision (Willcoxson, 1994).

In the absence of formal development programmes, there are three main ways of learning to supervise: (1) by being a postgraduate student, (2) through their own academic practice within a discipline, and (3) through trial and error at the interpersonal level where supervisors tread a delicate line between being supportive and critical at the same time. 
As a postgraduate student, supervisors have experienced the highs and lows of supervision firsthand. In a workshop it is not unusual to hear a comment such as:

'My Masters supervisor was one of the most appalling supervisors I have ever come across. The only thing he wanted was publications, results and he was not interested in his students at all. My Ph.D. was completely different because I actually had my project, I designed a project and found a supervisor who actually suited that project.'

What, in general, made these experiences poor is what one supervisor calls 'the deep-end principle':

'My own Ph.D. supervisor had total trust and faith in me, to a worrying point, where he believed things I was doing were right when I didn't believe they were right. So I was very much on my own. I wouldn't subject any of my students to that.'

These perceptions of poor supervision tend to describe supervisors who were not reflective of their own experiences. An attitude one coordinator at the University of Sydney has come up against is:

'Well, I had to go through that, why shouldn't they?'

These are supervisors who have formed the belief that preparation of a research thesis is a trial by fire and candidates have to be seen to struggle, otherwise their work cannot be original or at the cutting edge.

Reflection is equally critical for supervisors who have had positive experiences:

'I think I had a very good supervisor. I don't think I mirrored his particular style, but ... I think having a good role model at the time I was learning to supervise actually helped me.'

Without good models of practice, it is not surprising that most supervisors have been influenced by their own experiences, even if this simply provides a foil to oppose. 


\section{Online Academic Development}

With over 3000 graduate students at the Doctoral and Masters level, the University of Sydney is one of the leading research-orientated universities in Australia. The challenge for supervisor development in this environment is that supervisors come to academic development programmes with differing experiences, contexts and disciplinary expectations but are unable to see models of good practice. The University of Sydney Institute for Teaching and Learning meets this challenge by providing a range of resources to encourage supervisors to reflect on the consequences of supervisory practices through the Postgraduate Supervisors' Development Programme. This is a long-running and successful programme that was originally offered as a series of workshops aimed particularly at those who are new to supervision. Originally developed with seed funding made available by the Pro-ViceChancellor (Research), the programme moved to its new format when it faced the realities of limited funding which made an extensive programme of workshops unsustainable.

Interviews with successful supervisors clearly demonstrate that it is the supervisors' own supervision and reflecting on these experiences that has the greatest impact on what they do with their students. Simply understanding how successful supervisors learned to be effective has played a crucial role in designing a programme for the development of supervisors. With successful supervisors stressing the interpersonal relationship, co-learning and encouragement, it quickly became apparent that there is a need to be more than a repository of information on the University's regulations and policies. But neither could it focus simply on developing techniques and methods for effective supervision. The determining principle of the programme has been to demonstrate the diversity in supervisory practice, and to support supervisors in reflecting on how they compare to their own experiences of postgraduate supervision.

The multifaceted picture that emerged on the role of a supervisor provided the primary guidance in the appropriate process for postgraduate supervisor development. A supervisor is invariably described as a mentor, a facilitator and manager, guiding students to become independent researchers in their chosen field. Improvement of supervisory practice requires a programme that supports each of these roles. The programme also recognises that successful supervisors additionally have to keep up with disciplinary knowledge to be able to effectively 
mentor students into the discipline, but along with that they have a role in providing a structured environment and managing that process.

A survey of University of Sydney supervisors suggested the biggest barrier to participation in academic development was lack of time. The majority of supervisors unwittingly accept their first instance of supervisory responsibility rather than consciously choosing to supervise. It is not uncommon to be asked to co-supervise a student to provide an area of specialist expertise and to then find one taking over the responsibility for another supervisor's student. The almost accidental nature of starting to supervise means that most learn on the job. Often the busiest academics are also those with the most postgraduate students. With the increasing pressures on academic life today, supervisors are unable to prioritise academic development ahead of other responsibilities. Any postgraduate supervisor's development programme needs to be as flexible as possible at all levels to remove the barriers to participation perceived about the face-to-face workshop format.

Shifting to flexible delivery has been an evolutionary progression best described as a move from information sharing towards enquiry into postgraduate supervision. Each stage in this development may be seen as a focus on an increasingly more complex dimension of postgraduate supervision. The first phase involved information collection and dissemination, providing an easy access point to the University's regulations, policies and codes of practice. The second phase developed learning materials with activities to make sense of existing information on postgraduate supervision and to encourage reflection on practice.

The guiding principle of the current phase is to turn the obvious research abilities of supervisors towards researching their own practice. As the Faculties most represented in the programme are the health sciences, medicine and science, many participants have extensive experience in discipline-based research but limited experience in researching educational practices. While activity based, these modules were further enhanced with supporting online discussions and supervisor case studies. A problem-based approach to the Postgraduate Supervisors' Development Programme is an attempt to develop an educational solution from a process of systematic analysis that identifies the problem being solved, locates it within a broader research framework and applies a contextually appropriate educational solution. 


\section{Postgraduate supervisors' development programme}

The Postgraduate Supervisors' Development Programme is an innovative flexible learning programme supported with materials delivered via the Web (University of Sydney, undated). The programme represents an innovative approach to postgraduate supervision development in that it provides the opportunity to study where and when it suits the supervisor. The flexible learning programme aims to assist participants make sense of postgraduate supervision using a framework that models the learning processes of postgraduate students. In an effort to guide a more rigorous reflection of improving supervisory practice, a new learning environment has been developed to permit academic staff to set their own learning goals and arrange their own level of participation in the programme. Supervisors are asked to reflect on their journey to becoming a supervisor, drawing first on their own experiences of being supervised. The process is broken into four separate but related forms of enquiry starting with the descriptive research, followed by a validation in theory, which leads to describing the general principles of their supervision. In the final stage these principles are returned to their specific settings, students and tasks.

Guided by trigger questions, supervisors are encouraged to systematically construct (and reconstruct) their individual conceptual network of strategies and theories of supervision. The case studies of successful supervision enable participants to reflect on their supervisory practice, clarify their understanding of what constitutes effective supervision in their context, and share their insights and experience with colleagues from within and across disciplines. The key feature of the programme is its multi-layered design that emphasises collaboration within the entire university community. It is somewhat unique as an academic development programme in that it includes the involvement of senior academics of the university and postgraduate coordinators who contribute their time and resources to the programme. A challenge has been to maintain a balance between the strong commitment to the use of the experiences of the participants as the basis for reflection on supervision and to individualise the materials to meet the participant's particular background and interests. The programme is sustained through these different levels of interaction that equally engage novice supervisors and highly successful experienced supervisors alike.

The overall design of the programme is an integration of information on the regulatory requirements, practice and group activities. This provides a range of experiences that identify 
the key skills of successful supervisors and creates opportunities to transfer their application into practice. The programme is structured around a combination of the postgraduate supervisor's website, face-to-face workshops, and peer discussion and review. There are three corresponding activity areas in the programme: web-based resources, independent study modules and group-based activities.

\section{World Wide Web-Based Resources}

As a flexible learning programme an overarching goal has been to provide access to learning resources in a mode which permits participation at any time that suits time-constrained members of academic staff. Academics need to be able to engage with the programme in a timely manner according to their level of need, which may vary from the most straightforward contact details to the more complex, ethical questions regularly faced by supervisors, such as the ownership of intellectual property. The website reinforces the three levels of postgraduate supervision support identified in the programme. Consequently, there is a choice of three ways to access the online resources: by browsing through available material, enrolling to complete independent study modules, or participating in online discussions. In this way the participants make the choice about whether they simply need information on postgraduate supervision or access to skills development through structured learning experiences, or to contribute to a network of like-minded supervisors.

\section{Resource material on postgraduate supervision}

The browsing section of the website is open to anyone interested in postgraduate supervision. It is a source of links to reference material on postgraduate supervision, including the University of Sydney regulations, policies, the Postgraduate Supervisors Handbook, and links to appropriate committees and associations, such as the Sydney University Postgraduate Student's Association (SUPRA). It contains bibliographic references, links to government reports, case studies submitted by successful supervisors plus handouts and issue papers from the workshops.

The purpose of these resources is to demonstrate the institutional expectations and standards of successful supervision. It attempts to represent the diversity in the university culture of postgraduate research supervision. In so doing it maintains participation of high-ranking, 
experienced and successful supervisors of the University such as the workshop presenters who provide resources they consider relevant to the new supervisors.

\section{Independent Study Modules}

There are six independent study modules, each taking at least an hour of study time. The modules are designed for supervisors who would like to work through the resource material in a more formalised course of study. They present a process by which the standards and expectations demonstrated by successful supervisors may be met. Case studies of successful supervision are integrated into the self-study material and are also made available in the resources section of the website. Supervisors who would like their participation in the programme formally assessed do so by developing their own case study, which is made available through the resources section.

The independent study modules present a series of self-assessment activities on key issues of postgraduate supervision. They are organised around six stages of supervision: getting started, first meeting, managing the process, the end of year review, writing, and finishing. Each stage is framed by trigger material with activities to assist supervisors to understand fully the issues relevant to this stage of postgraduate supervision. Exploration of the questions raised by the trigger material is supported by other elements of the programme (web-based resources, faceto-face workshops and peer discussion).

Working through the activities provides the foundation for participants to document their supervisory practice. This then contributes to the reference section as case study material. Although designed as a coherent programme, modules maybe accessed individually to address a particular need. The most frequently accessed modules focus on preparing for the end-of-year review followed by preparing for supervision.

Participants in the programme reported that engaging with the material in the modules assisted them to gain a better understanding of the constitution of Masters and Ph.D. programmes. It also helped to define the student-supervisor relationship and cement ideas about the importance of good communication. The modules additionally assisted some supervisors in developing a research culture among students. In one case, this was so 
successful that the facility involved decided to further support the development of postgraduate research skills through the appointment of a sub-dean.

\section{Participants' learning goals}

The programme is password protected and requires formal registration to receive access to the modules. By registering in the programme, supervisors signal a commitment to study postgraduate supervision. Registration provides an opportunity for participants to set their own learning goals. It also permits the programme coordinator to identify participants' specific needs and negotiate with them their level of involvement, target the resource materials to their interests and provide support to individual supervisors by addressing their questions and concerns. Registered participants are automatically notified of workshops, contact details of other registered participants, reports from support group activities and material provided by guest presenters.

Registration involves a brief questionnaire in which supervisors indicate their interest in postgraduate supervision and participants are asked to nominate a date when they would like to be removed from the registration list. The learning goals submitted by the supervisors have a two-pronged role. They provide the ITL with a record of the important issues currently facing supervisors. Moreover, it is an opportunity for supervisors on the area they need to engage with in the programme, in a replication of the fine-tuning of research questions. To date supervisors have indicated a wide range of learning goals. These include:

- Giving advice in planning and structuring research material.

- Establishing what is required of both the student/supervisor in terms of interaction and goals.

- Motivating discouraged students.

- Stimulating candidates to publish research.

- Understanding the administrative requirements of the various stages of the Ph.D.

- Encouraging students to think critically.

- Finding the line between guiding and instructing.

- Assessment and development of candidates' competencies to complete projects.

- Provision of constructive feedback.

- Policies at departmental level for supervisory practice. 


\section{Group-based Activities}

A difficulty created by the implicit nature of postgraduate supervision practices is the uncertainty of the reasons some practices work and this makes it difficult to transfer them to other supervisors, other problems or other social settings. While supervisors have traditionally used their personal experiences developed through insight and trial and error to build the craft of their personal knowledge that is useful in their own particular area, a lack of reflection, as was suggested above, allows supervisors to hear what they expect to hear (research is hard), rather than what is actually being said (I need some help).

With the awareness that learning is both situated and progressively developed through activity (Wenger, 1998), group learning becomes the mechanism for promoting a deeper understanding of the supervisor's own approaches to postgraduate supervision through collaborating on complex problems. The programme provides two opportunities for supervisors to have their assumptions challenged in light of their decision-making as a key to refining their personal knowledge.

The first of these is the online discussion forum wherein the website supports peer interaction so that supervisors may discuss issues of postgraduate supervision. An email list of all registered participants is maintained for administrative purposes, such as announcing updates to the website and publicising events such as workshops. Workshop presenters' notes are also made available through a posting in the forum. There are structured discussions facilitated by a moderator discussing his or her own contribution in the form of a short paper or the implications of some wider issue in the academic research community. Participants are also invited to contribute their responses to wider issues in the higher education sector to do with postgraduate supervision which are collected and included with the resources materials.

The discussion forum runs independently but parallel to the independent study materials and maintains the cross-disciplinary nature of the programme. It is in this forum that the results of the independent study activities may be posted or general issues of interest discussed. While the initial design anticipated that there would be a need for a collegial environment to discuss issues of postgraduate supervision, when surveyed on their use of the online forum, participants were more likely to report informal and naturally forming peer support groups 
formed as the consequence of participating in the programme. It was found that after sharing ideas on the online discussion, supervisors tended to telephone colleagues identified online and arrange to meet informally to talk over issues.

\section{Workshops}

As a programme of study the PGSDP has always been conceived of as more than just placing information about workshops and their handouts on a website. By the same token, the feedback from earlier workshops indicated that meeting face-to-face still fulfilled a need, with the participants describing workshops as overwhelmingly 'worthwhile' and 'worthy of support'. Attendance was intermittent mainly due to the large time commitment of the workshops.

Each year the programme schedules two face-to-face workshops during the non-teaching time in each semester. Workshops provide an alternative mechanism for supervisors who prefer to come together to discuss postgraduate supervision. The workshops are opportunities for participants to hear examples of successful supervision, discuss issues related to their own practice and to work through case study material. It is also a chance to cross faculty and departmental boundaries to explore the context of supervision and its relation to all other academic responsibilities. Comparing the humanities and science-based case histories, for example, always fuels a lively discussion of the purpose behind a research thesis.

The themes of the workshops reflect the two major strategies for learning to supervise identified by experienced supervisors. One workshop focuses on the roles and responsibilities of supervisors. It provides training in skills for small group learning in preparation for the establishment of peer support groups. The other workshop focuses on the interpersonal skills required to structure and manage the supervision process. Activities to practise key skills include communicating with students, dealing with problems and providing meaningful feedback. In addition, it is an opportunity to take stock of the programme and the participants' learning goals. Both workshops provide information, case studies of effective supervision and opportunities to practise these skills so that participants may take away ideas and examples of strategies to implement in their own practice. 
For the ITL, workshops help develop a profile for quality supervision within the University and are an invaluable source of informal feedback from workshop participants. It also allows supervisors to gauge their own approach, relative to the wider university community. Participants in the workshops invariably ask for more opportunities for group discussion, particularly after hearing case histories of successful supervision from experienced supervisors. They enjoy exploring a range of supervisory situations and expectations of supervisors. By hearing from successful supervisors and being able to discuss problems and strategies, the workshops showcase the firsthand observations of experienced supervisors as well as modelling effective supervision.

\section{Future Challenges for the Programme}

Feedback from participants, coordinators and senior academics of the University indicates that the programme continues the good work begun by the earlier workshops, with the added flexibility of modules which 'allows thinking about the principles of postgraduate supervision outside the workshop format'. The multiple points at which the programme is now entered, plus the data which indicate that the programme is reaching a substantially broader crosssection of academic staff, justify the shift to a flexibly delivered programme.

Participants in the programme have reported adopting strategies in their practice such as seeing students more regularly, offering clearer documentation of meetings with students, and listening more carefully to what students are saying. The independent study materials and online resources (discussion and resource section) provide a range of learning tools that are reportedly migrating into supervisory practice. Many are now aware of the importance of introducing new students to postgraduate networks and consider the development of mentorship schemes between new and experienced candidates. This indicates that participants in the Postgraduate Supervisor Development Programme are looking at issues of the structure of the supervisory relationship, which is a positive outcome in light of the aims of the programme.

For a sustained improvement in supervision practice the strong record of supervisor support of many of the University's schools and departments needs be implemented across the University as a whole. Postgraduate coordinators play the key role in providing support for the development of postgraduate supervisors at a local level, while some coordinators 
acknowledged that there was an increased intensity in the department related to the importance of supervisory responsibilities. This intensity was due partly to students becoming more assertive in understanding what was expected in the relationship. Support groups continue to be set up in a number of departments.

All coordinators commented that they had been receiving publicity regularly (emails and print publicity) from the ITL in relation to workshops. A few coordinators were not aware that part of the programme was being delivered online through web-based modules. One coordinator encouraged two staff members of the department to attend and then facilitate an academic development morning on supervision. In this instance, staff who attended the workshop encouraged others to access the web-based materials.

Perhaps the greatest challenge for the future of the programme will be to overcome the time pressures so often mentioned as a limiting factor in staff accessing the programme and putting these principles into practice. Feedback from participants has pointed to the need for more structure in online discussions to ensure higher levels of participation. Continued collaboration with the postgraduate coordinators and rewarding supervisors' participation in the programme are two important strategies for the programme as it moves into its next stage of development.

\section{Conclusion}

The Postgraduate Supervisors' Development Programme has demonstrated that it is possible to use online academic development as a means to provide new and experienced supervisors with an opportunity to engage in discussion and reflection relating to postgraduate supervision. A steady increase in the number of supervisors registered to complete the programme demonstrates that the combination of the workshop programme and web-based resources continues to meet the diverse needs of postgraduate supervisors at the University of Sydney. The web-based resources allowed supervisors to complete the programme in their own time while addressing their immediate learning goals. Workshops provide the important opportunity to interact with supervisors from other schools and departments, and to share experiences of successful supervision. This is an endorsement for the individualised, negotiated, sometime serendipitous curricular structure that tries to capture the tenor of the nature of supervision by providing supervisors with the maximum choice, and that also 
acknowledges their status within their disciplines, while doing so in the context which meets the regulatory responsibilities the University has set for quality supervision of its students.

\section{Acknowledgement}

The author would like to acknowledge the work of Tai Peseta for her work in developing the successful supervisor case studies, supporting the programme and collecting all the evaluative data.

\section{References}

Acker, S., Hill, T. and Black, E. (1994) Thesis supervision in the social sciences: managed or negotiated? Higher Education, 28, pp. 483-98.

Delamont, S., Atkinson, P. and Parry, O. (1997) Supervising the PhD: A Guide to Success. Buckingham: The Society for Research into Higher Education and Open University Press.

Grant, B. and Graham, A. (1994) Guidelines for discussion: a tool for managing postgraduate education. In Zuber-Skerritt, O. and Ryan, Y. (eds) Quality in Postgraduate Education. London: Kogan Page. Moses, I. (1985) Supervising Postgraduates. Campbelltown: HERD SA.

Kandlbinder, P. \& Peseta, T. (1999) In Supervisors' Words: An Insider's View of Postgraduate Supervision. Sydney: Institute for Teaching and Learning.

Pearson, M. (1999) The changing environment for doctoral education in Australia: implications for quality management, improvement and innovation. Higher Education Research and Development, 18 (3), pp. 268-87.

Phillips, E. and Pugh, D. (1994) How to get a PhD. Buckingham: Open University Press.

Stevens, K. and Asmar, C. (1999) Doing Postgraduate Research in Australia. Melbourne: Melbourne University Press.

Wenger, E. (1998) Communities of Learning. Cambridge: Cambridge University Press.

Willcoxson, L. (1994) Postgraduate supervision practices: strategies for development and change. Higher Education Research and Development, 13 (2), pp.157-66. 